Afr. J. Trad. CAM (2006) 3 (1): 1 - 10

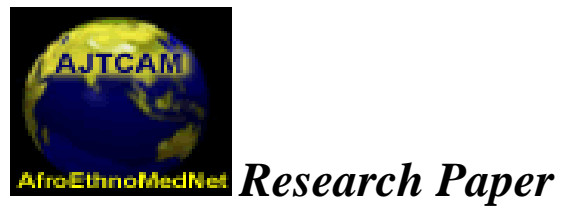

Afr. J. Traditional, Complementary and Alternative Medicines www.africanethnomedicines.net

ISSN 0189-6016@2005

\title{
DETERMINATION OF PESTICIDE RESIDUES IN KHAT LEAVES BY SOLID-PHASE EXTRACTION AND HIGH-PERFORMANCE LIQUID CHROMATOGRAPHY
}

\author{
Ali, Awadh N.A. ${ }^{\text {ab }}$, Lemme, D. ${ }^{\text {, }}$ Jira, Th.* ${ }^{c}$, Attef, O. ${ }^{\text {d }}$ and Al-rahwi, K. ${ }^{\text {a }}$ \\ ${ }^{a}$ Pharmacognosy Department, Faculty of Medicine and Health Sciences, Sana'a \\ University and ${ }^{\mathrm{b}}$ Aden University, Yemen; ${ }^{\mathrm{C}}$ Pharmaceutical/Medicinal Chemistry, \\ Institute of Pharmacy, Ernst-Moritz-Arndt-University, D-17487 Greifswald, Germany; \\ ${ }^{\mathrm{d}}$ Department of Pharmacognosy and Pharmaceutical Chemistry, Ajman University \\ of Science and Technology Network, Ajman, U. A. E. \\ *E-mail: jira@uni-greifswald.de
}

\begin{abstract}
The purpose of this investigation is to develop a simple method for the assessment of pesticides in Khat leaves, Catha edulis FORSK. (Celastraceae) shrub, chewed by about $60 \%$ of the Yemeni people, producing amphetamine-like psychostimulation. The first procedures involve solid-phase extraction using Adsorbex ${ }^{\circledR}$ RP-C18 and Bakerbond ${ }^{\circledR}$ RP-C18 disposable cartridges with $40 \%$ acetonitrile for elution. Isocratic and gradient analysis was carried out by means of high-performance liquid chromatography using different stationary phases to analyse methidathion, peconazole and dimethoate. An Ultrasphere ${ }^{\circledR}$ ODS RP-18-column with UV-detection at $210 \mathrm{~nm}$ and $80 / 20 \%$ (v/v) acetonitrile/water as mobile phase (isocratic) was used to determine the content of methidathion, peconazole and dimethoate (detection limit 20-25 ng). The method was validated with fortified samples at pesticide concentration of $0.1 \mathrm{mg} / \mathrm{ml}$. Average recoveries ranging from 97.9 and $101.6 \%$ with a relative standard deviation (RSD) of 1.7-3.8 \%. Each recovery analysis was repeated four times. Limits of detection ranged from the analytical procedures were applied to 5 samples of khat and no detectable amounts of pesticides were found in any sample under the conditions described.
\end{abstract}

Key words: Khat leaves, methidathion, penconazole , dimethoate, pesticides, Catha edulis 
Afr. J. Trad. CAM (2006) 2 (3): 1 - 10

\section{Introduction}

The pesticide pollution of the environment plays generally a crucial role in the occurrence of many diseases affecting plants, animals and man. One of the main factors causing pollution of the environment is the irrational use of pesticides.

In Yemen, this factor constitutes one of the main causes for contamination of the environment particularly by the Khat farmers. There is a widespread practice among people living in Yemen of chewing the leaves of Khat shrub, which produces amphetamine-like psychostimulation and increase in sympathomimetic tone due to its alkaloid content such as cathinone (Szendrei 1980, Kalix 1992).

The purpose of this work was to develop methods for the determination of residues from three pesticides used in Khat cultivation. The methodologies are based on solid-phase extraction (SPE) and high performance liquid chromatography (HPLC) with UV-detection to determine methidathion, dimethoate and penconazole (Figure 1).

\section{Experimental}

\section{Chemicals and materials}

Acetonitrile (ACN, HPLC gradient grade, Promochem, Wesel), n-hexane and methanol (MeOH, HPLC grade, Applichem, Darmstadt), acetone (Merck, Darmstadt), dichlormethane (DCM), dimethylether (Riedle-de Häen AG, Seelze). HPLC-grade water was doubly distilled. Reference standards of dimethoate, methidathion and penconazole pesticides were friendly gifted by BASF Agro (Limburgerhof, Germany) and Novartis Crop Protection AG (Münchwilen, Switzerland). All standards were at least $98 \%$ pure. Standard pesticide solutions were prepared by dissolving $100 \mathrm{mg}$ of the standard pesticide in $100 \mathrm{ml} \mathrm{ACN}$ or $\mathrm{MeOH}$, and stored in dark containers. The working standard solutions were prepared by diluting the stock solutions as required.

Sodium chloride, silica gel, medical charcoal, and sodium sulfate (Merck, Darmstadt) were analytical-grade reagents. Adsorbex ${ }^{\circledR}$ (RP-18 100 mg, RP-8 100 mg; Merck, Darmstadt), Bakerbond ${ }^{\circledR}$ (RP-18 500 mg, RP-8 500 mg, Cyano 500 mg, Diol 500 mg; J.T. Baker Inc., Phillipsburg, USA).

\section{Apparatus}

Shimadzu high-performance liquid chromatograph equipped with two solvent delivery pumps (LC-10AD), SPD-M10A diode array detector (SPD-M10A), integration with CLASS-10 Software from Shimadzu. Stainless steel analytical columns were LiChrosorb ${ }^{\circledR}$ RP-2, 250 x 4.6 mm I. D., $5 \mu$ (Merck, Darmstadt); Ultrasphere $^{\circledR}$ ODS RP-18, 250 x 4.6 mm I. D., $5 \mu$ m (Beckman, USA); Caltrex ${ }^{\circledR}$-BI, 200 x 4.6 mm I. D., 10 mm (Synaptec GmbH, Greifswald, Germany).

\section{Sample preparation and fortification}

Catha edulis (Ce) leaves with tender stemlets (Samin variety) used for this study were collected in May 2000 from Khat farms located in outskirts of Dalah town in Dalah province. It was identified by Dr. AlFakieri, M., Faculty of Science, Aden University. Authentic specimen (DCP0-DCP5), were deposited at the Department of 
Afr. J. Trad. CAM (2006) 3 (1): 1 - 10

Pharmacog-nosy, Faculty of Medicine and Health Sciences, University of Sana'a, Yemen. Khat samples consisting of fresh leaves with tender stems sprayed with methidathion, penconazole, dimethoate (DCP1-DCP5) and pesticide free sample (DCP0) were also collected in May 2000, air-dried and sent by airmail for analysis.

The Khat plants were sprayed with the pesticides approx. 20 days before harvesting..

The dried, ground Khat samples were subjected to different extraction methods for isolating the pesticides. Fortified samples were prepared by adding standard solution at concentration of $0.01 \mathrm{mg} / \mathrm{ml}$ to pesticide free Khat sample (DCP0).

\section{Method I ( "Pesticide Analytical Manual E4”, U.S. FDA)}

$10 \mathrm{~g}$ dried Khat leaves (equivalent to $50 \mathrm{~g}$ fresh plant) were ground and extracted with $70 \mathrm{ml} 65 \%$ acetone/ water under continuous shaking for $10 \mathrm{~min}$. The filtrate was made up to $100 \mathrm{ml} 65 \%$ acetone solution; $\mathrm{NaCl}$ was added to $50 \mathrm{ml}$ of the filtrate in a separating funnel and shaken with DCM (2x); the combined DCM layers were dried over anhydrous $\mathrm{Na}_{2} \mathrm{SO}_{4}$, and evaporated in vacuo. The residue was dissolved in $40 \%$ ACN and an aliquot (50 $\mu \mathrm{l}$ ) was analysed by HPLC (Luke and Doose, 1983).

\section{Method II (Becker and Schug)}

The extraction was performed as described in method I with the difference that the residue of DCM was applied on a column packed with a mixture of silicagel, active charcoal and $\mathrm{Na}_{2} \mathrm{SO}_{4}$ and eluted with $15 \mathrm{ml}$ of DCM. The eluate was evaporated in vacuo. The residue was analysed with HPLC - as described in method I (Becker and Schug 1990).

\section{Method III (“California Department of Food and Agriculture”)}

The extraction was performed as described in method I but with $70 \%$ acetonitrile. $500 \mathrm{mg}$ Bakerbond ${ }^{\circledR}$ RP-18-SPE cartridge was preconditioned with $10 \mathrm{ml}$ ACN and 2 ml water; the sample was transferred to the cartridge and allowed to elute dropwise by applying a slight vacuum. The eluate was collected. Liquid-liquid extraction between aqueous layer and ACN-layer was performed by adding to eluate in a separatory funnel phosphate buffer solution and saturated $\mathrm{NaCl}$ solution. The ACN-phase was evaporated in vacuo (Lee et al. 1991). The residue was analysed with HPLC as described in method1.

\section{Method IV}

The extraction was performed as described in method I but with 70\% ACN.

The collected DCM layers were shaken with phosphoric acid solution. The organic layer was dried over $\mathrm{Na}_{2} \mathrm{SO}_{4}$, and evaporated in vacuo. The residue was analysed with HPLC as described in method I.

\section{Method V}

The extraction and concentration under vacuum was done as in method IV. $500 \mathrm{mg}$ Bakerbond $^{\circledR}$ RP-18-SPE cartridge was preconditioned with $10 \mathrm{ml}$ ACN and $2 \mathrm{ml}$ water; 
Afr. J. Trad. CAM (2006) 3 (1): 1 - 10

the obtained extract was transferred to the cartridge and allowed to elute and the eluate was discarded and the cartridge was washed with $5 \mathrm{ml} 5 \%$ ACN. The eluation was carried out with $5 \mathrm{ml} 80 \%$ ACN-water mixture and the eluate was concentrated and analysed with HPLC..

\section{Pesticides Sample Preparation}

Standard pesticide solutions were prepared by dissolving $100 \mathrm{mg}$ of the standard pesticide in $100 \mathrm{ml} \mathrm{ACN}$ or $\mathrm{MeOH}$ and stored in dark containers. Dilution series of 0.1 and $0.01 \mathrm{mg} / \mathrm{ml}$ were prepared.

\section{Chromatographic Conditions}

Isocratic and gradient elutions were performed to optimize the chromatographic separation of the pesticides from other ingredients of the Khat samples.

a) Isocratic Elution

Column: $\quad$ Ultrasphere ${ }^{\circledR}$ ODS RP-18 (Beckman)

Mobile Phase: ACN/Water (80:20, v/v);

Flow Rate: $0.4 \mathrm{ml} / \mathrm{min}$; Temperature: $40^{\circ} \mathrm{C}$

Injection Volume: 50 l; Post Time: 15 min; Detection: $210 \mathrm{~nm}$

b) Gradient Elution

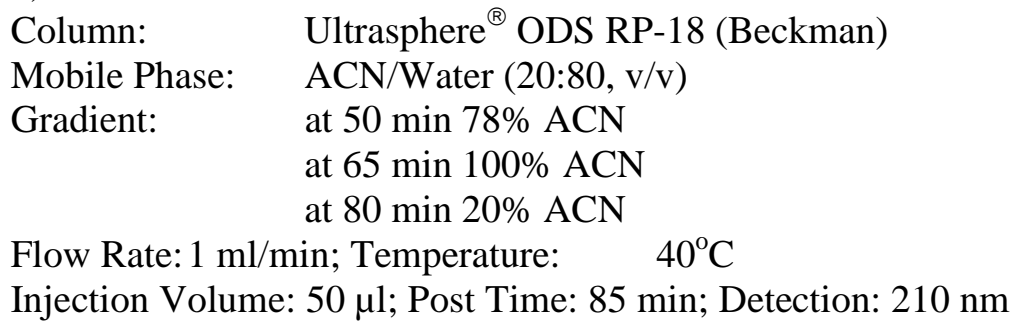

\section{Results and Discussion}

Extraction method for investigating the dried leaves and stems of Catha edulis as well as quantitative HPLC method were developed and validated.

Based on the official regulations about the maximal allowed load of pesticides in dried crude drug, UV-absorption of the studied pesticides was determined and showed that the expectable existing small concentration of pesticides in the real sample was detectable.

\section{Comparison between SPE and liquid- liquid-extraction}

In order to develop extraction method which facilitates the pesticide determination in Khat, partitioning behavior of pesticide standard solution on SPE and on liquid-liquid extraction were studied. However the liquid-liquid extraction delivered average recoveries ranged from 80 - $103 \%$ for all pesticides by using water/DCM (Table 1). 
Afr. J. Trad. CAM (2006) 3 (1): 1 - 10

The solid-phase extraction was preferred because of its simplicity, robustness, it avoids the drawbacks, such as the use of large amounts of solvents, and the occurrence of troublesome emulsions. $40 \% \mathrm{ACN}$ and $100 \% \mathrm{ACN}$ were

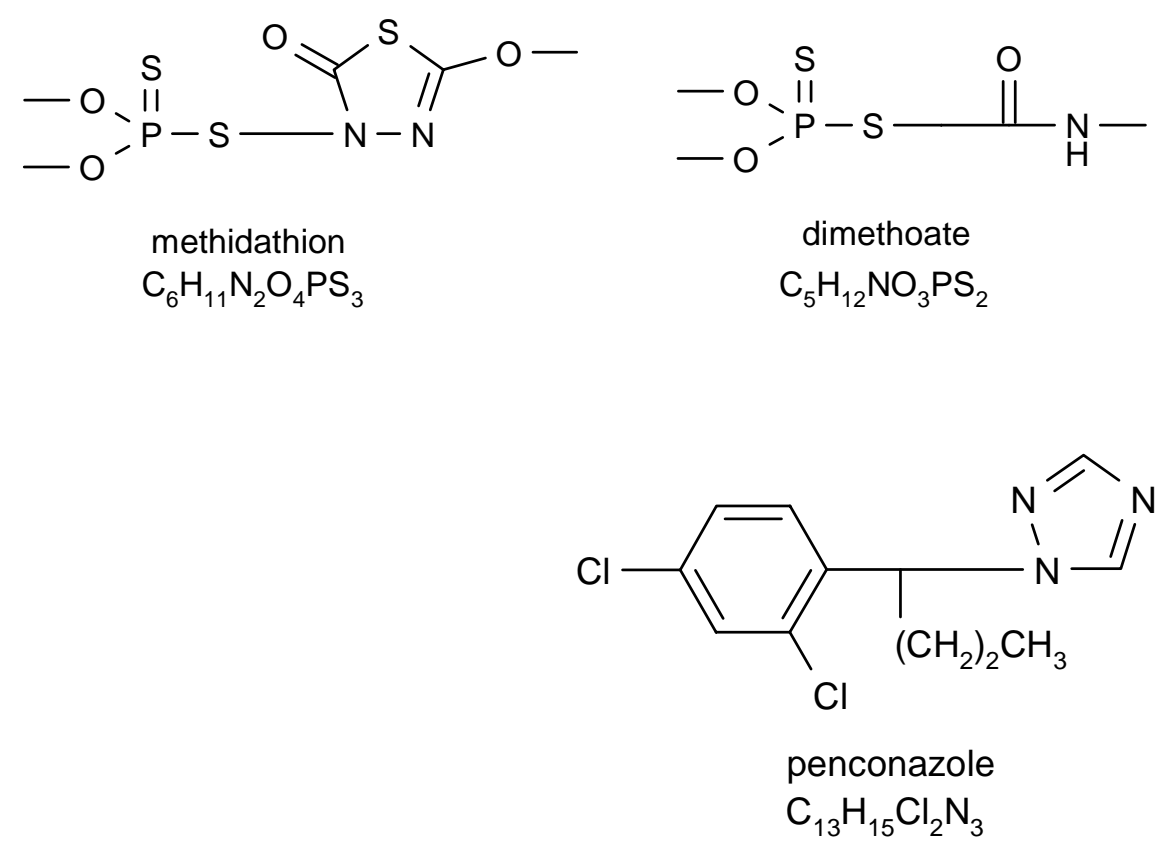

Figure 1: Structures of the pesticides

Table 1: Recovery of pesticides by using liquid-liquid-extraction (water/DCM) $(\mathrm{n}=9)$

\begin{tabular}{|c|c|}
\hline pesticide & recovery rate (\%) \\
\hline dimethoate & 89.8 \\
\hline methidathion & 80.8 \\
\hline penconazole & 100.6 \\
\hline
\end{tabular}

selected for methidathion, penconazole elution from100 mg RP-18 SPE and $80 \%$ ACN for dimethoate elution from $500 \mathrm{mg}$ RP-18 SPE, because the solvents at these concentrations provided higher recoveries for the pesticides in comparison to other dilutions of ACN $(0 \%, 10 \%, 20 \%)$. No influence on the SPE recovery of pesticides has been observerd by changing the applied concentrations of pesticides $(0.1,0.01$, and $0.001 \mathrm{mg} / \mathrm{ml}$ ), the modification of $\mathrm{pH}$-value and ion strength of the wash and sample 
Afr. J. Trad. CAM (2006) 3 (1): 1 - 10

solutions. But influence has been observed on pesticide recovery averages by using cartridges from different companies. Bakerbond ${ }^{\circledR}$ RP-18-cartridge, $500 \mathrm{mg}$ was principally the efficient method, through which the three pesticides penconazole, methidathion, dimethoate were isolated.

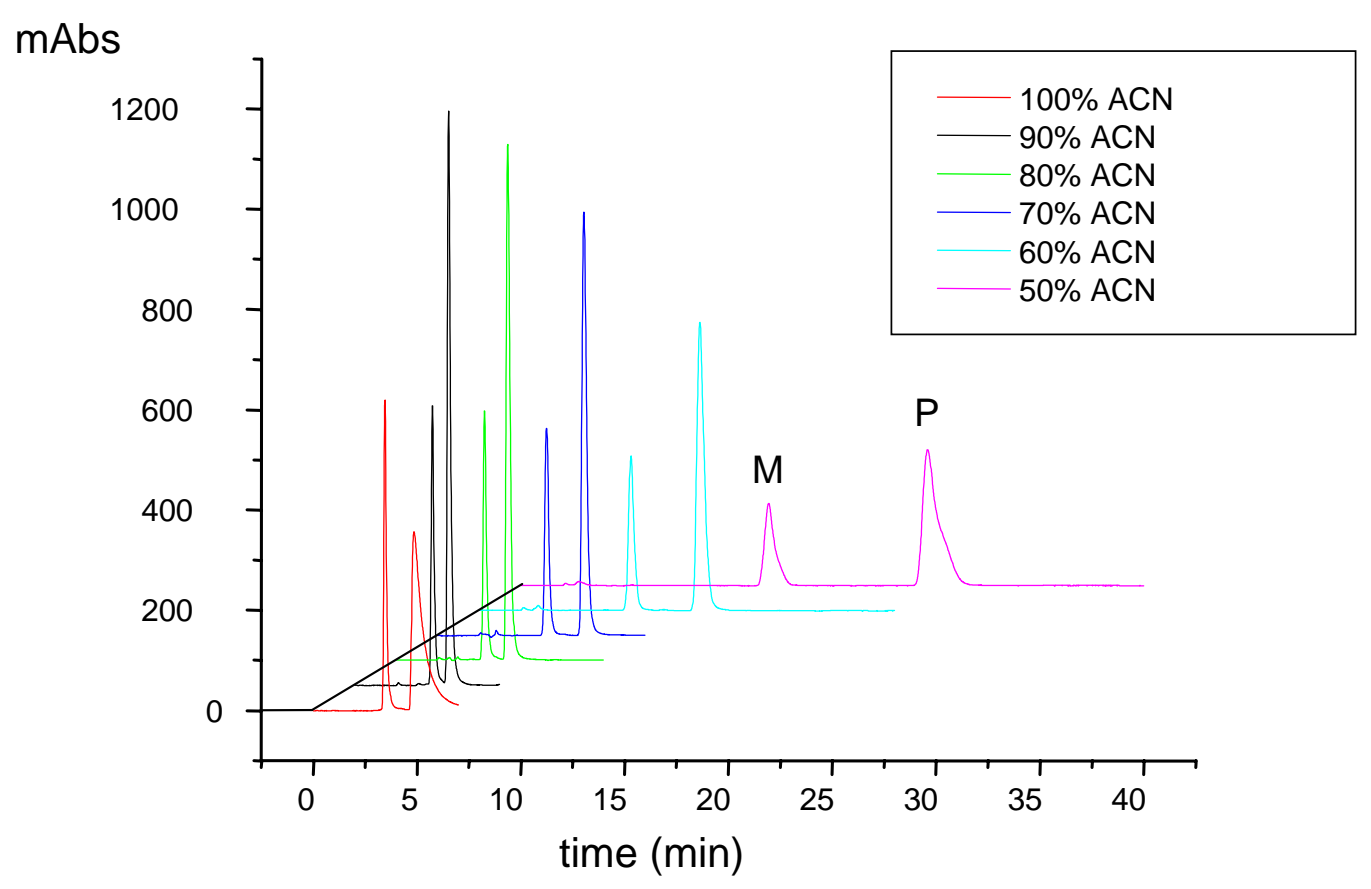

Figure 2: Influence of ACN-concentrations on the retention time of methidathion and penconazole chromatographic conditions:

Mobile phase: ACN/water, flow 0,8 ml/min, injection volume $50 \mu \mathrm{l}$, concentration $0,01 \mu \mathrm{g} / \mu \mathrm{l}, \mathrm{t}_{0(\mathrm{ACN})}=2,15 \mathrm{~min}$; detection: $\left.210 \mathrm{~nm}\right) \mathrm{M}$ : methidathion, $\mathrm{P}$ : penconazole

\section{Optimization of the HPLC-UV parameters}

In order to establish the optimum of isocratic and gradient chromatographic analysis conditions of methidathione, penconazole and dimethoate standard solutions, a UV-detector at $210 \mathrm{~nm}$ was used. To evaluate the mobile phase, different ratios of (ACN-water and $\mathrm{MeOH}-$ water, see Figure 4) were tested with respect of optimal peak sharpness, separation efficiency and lower UV-absorption at the used detection wave length. The composition of ACN/ water (80/20 $\%, \mathrm{v} / \mathrm{v}$ ) at flow rate of $0.4 \mathrm{ml} / \mathrm{min}$, proved to be the most suitable mobile phase with respect to peak form, time of analysis and chromatographic separation of the three pesticides in pesticide standard solutions (Figure 2). Gradient elution has been used for investigating fortified Khat extracts. From RP-18, RP-2- and calixarene stationary phases which were tested, RP-18 showed the best separation with the above mentioned solvent.

\section{Choice of the optimal method for extracting pesticides from Khat samples}

Pesticide standard solution and fortifed Khat sample have been used for evaluating the best extraction method. The best clean up (selective) results were achieved by using the method II.. Both methods III and V were not able to remove mid polar substances. 
Afr. J. Trad. CAM (2006) 3 (1): 1 - 10

By comparing the obtained recovery averages of each method, it was found that the recovery averages were decreased with increasing clean up steps.

Table 2: Recovery rates of pesticide standard solution (conc. of $0,01 \mathrm{mg}$, b: recovery rate of Khat sample fortified with $0,01 \mathrm{mg}$ pesticide by using different extraction methods)

\begin{tabular}{|r|c|c|c|c|c|c|}
\hline \multirow{2}{*}{ method } & \multicolumn{2}{|c|}{ dimethoate } & \multicolumn{2}{c|}{ methidathion } & \multicolumn{2}{c|}{ penconazole } \\
\cline { 2 - 7 } & $\mathrm{a}$ & $\mathrm{b}$ & $\mathrm{a}$ & $\mathrm{b}$ & $\mathrm{a}$ & $\mathrm{b}$ \\
\hline $\begin{array}{r}\text { method I ("Pesticide Analytical } \\
\text { Manual E4“ /U.S. FDA-method) }\end{array}$ & 95,6 & $\mathrm{nd}$ & 101,8 & $\mathrm{nd}$ & 102,5 & $\mathrm{nd}$ \\
\hline $\begin{array}{r}\text { method II (Becker/Schug) } \\
\text { Food and Agriculture”) }\end{array}$ & 82,8 & $\mathrm{nd}$ & 102,4 & 88,6 & 102,4 & $\mathrm{nd}$ \\
\hline $\begin{array}{r}\text { method III („California Dept. of } \\
\text { method IV }\end{array}$ & 85,4 & $\mathrm{nd}$ & 86,3 & $\mathrm{nd}$ & 83,6 & $\mathrm{nd}$ \\
\hline method V & 91,2 & nd & 79,1 & nd & 82,0 & nd \\
\hline
\end{tabular}

nd: not determinable

The best recovery averages (efficiency) were recorded by using method I and V, which have only one clean up steps either liquid-liquid extraction or solid phase extraction.

Clean up problems were observed with extraction and HPLC analysis of fortified Khat sample nearly in all methods, where interfering peaks of Khat constituents in UV spectra hinder the residue analysis of pesticides. Best purification results were achieved by modified method II where the recovery values of methidathion in the fortified plant extract estimates $88.6 \%$ (Table 2).

Modified method II was suitable to determine pesticides having little or no aromatic structural properties in Khat sample, but it was not suitable to determine penconazole either in pesticide standard solution (recovery averages $36.4 \%$ ) or in fortified Khat extract because of its chemical structure

The accuracy was calculated as a percentage of recovery ranging from 97.9 and $101.6 \%$ with relative standard deviation (RSD) of 1.7 - $3.8 \%$. Each recovery analysis was repeated four times, the precision and accuracy were considered adequate for the validation of the method.

Under the chromatographic conditions described, calibration curves were constructed by plotting peak areas versus concentrations. Good linearity and good correlation coefficient $(\mathrm{C} . \mathrm{V} .=0.99)$ were achieved for the three pesticides. 
Afr. J. Trad. CAM (2006) 3 (1): 1 - 10

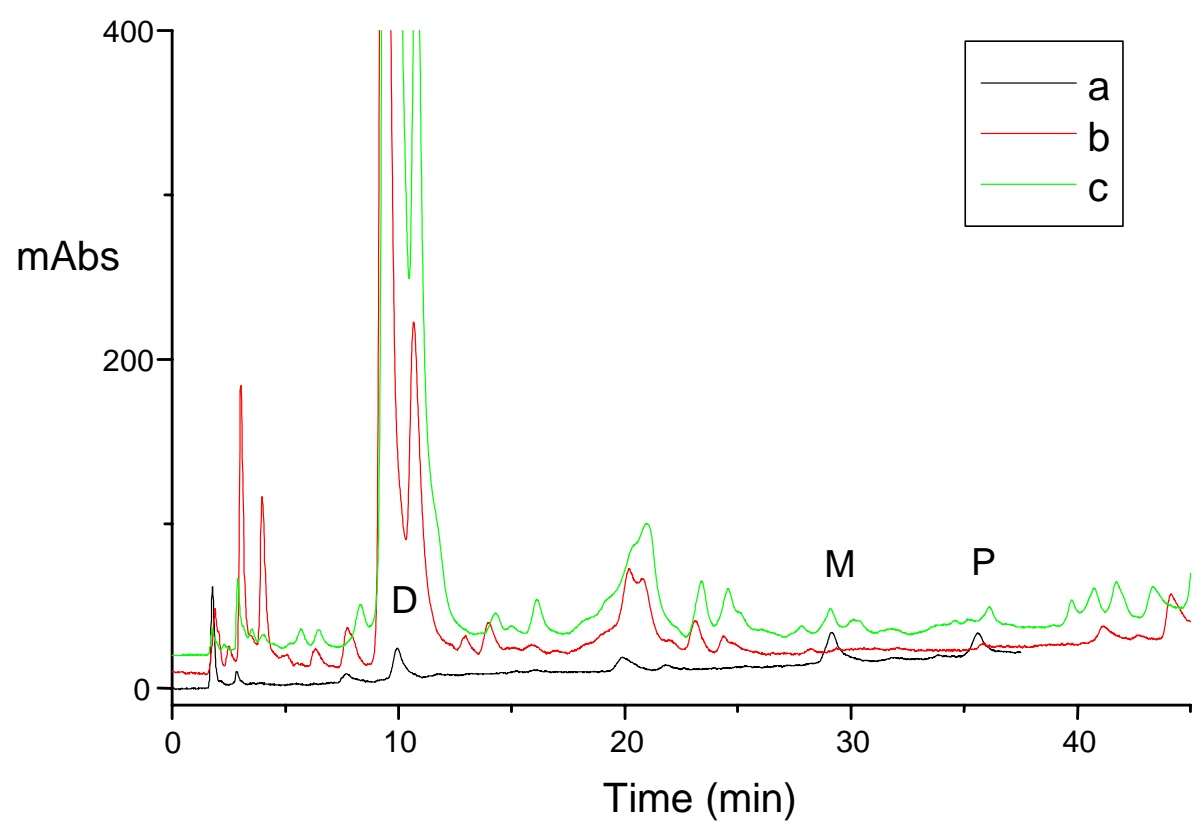

Figure 3: HPLC - chromatogram of pesticides

a: pure pesticide standard solution (conc. $0,01 \mathrm{mg} / \mathrm{ml}$ )

b: pure Khat extract

c: Khat extract fortified with each pesticide $(0,01 \mathrm{~m}$

Chromatographic conditions:

Stat. Phase: Ultrasphere ${ }^{\circledR}$ ODS RP-18 (Beckman)

Mobile Phase: ACN/Wasser combinations,

flow rate $1 \mathrm{ml} / \mathrm{min}$, detection $210 \mathrm{~nm}$, injection volume $50 \mu \mathrm{l}$

\section{Real samples}

The proposed method was applied to the analysis of 5 real khat samples (dried leaves and young stems). None of the target analytes were detected in these samples under the experimental conditions described. For further investigations in the future, it is adviseable to use fresh materials and only the young leaves and tender stems used for chewing.

\section{Conclusion}

A modified methodology allows an efficient and rapid determination of pesticides in Khat samples by means of SPE and HPLC. An isocratic elution and a gradient elution method on RP-18 phases with ACN/water eluents were used for the quantitative evaluation of pesticides. The method was checked with regard to its precision, correctness and robustness and the concentration of pesticides was determined by means of an external standard. 
Afr. J. Trad. CAM (2006) 3 (3): 1 - 10

Since Khat chewing consumption is increasing and literature does not describe chromatographic methods for determination of pesticide residues in the matrix, the proposed procedures could be applied for monitoring programs for Yemeni Ministry of Health to study this social and enviromental problem deeply. Further studies are necessary to optimize the proposed procedures for analysing different groups of pesticides used for spraying Khat leaves.

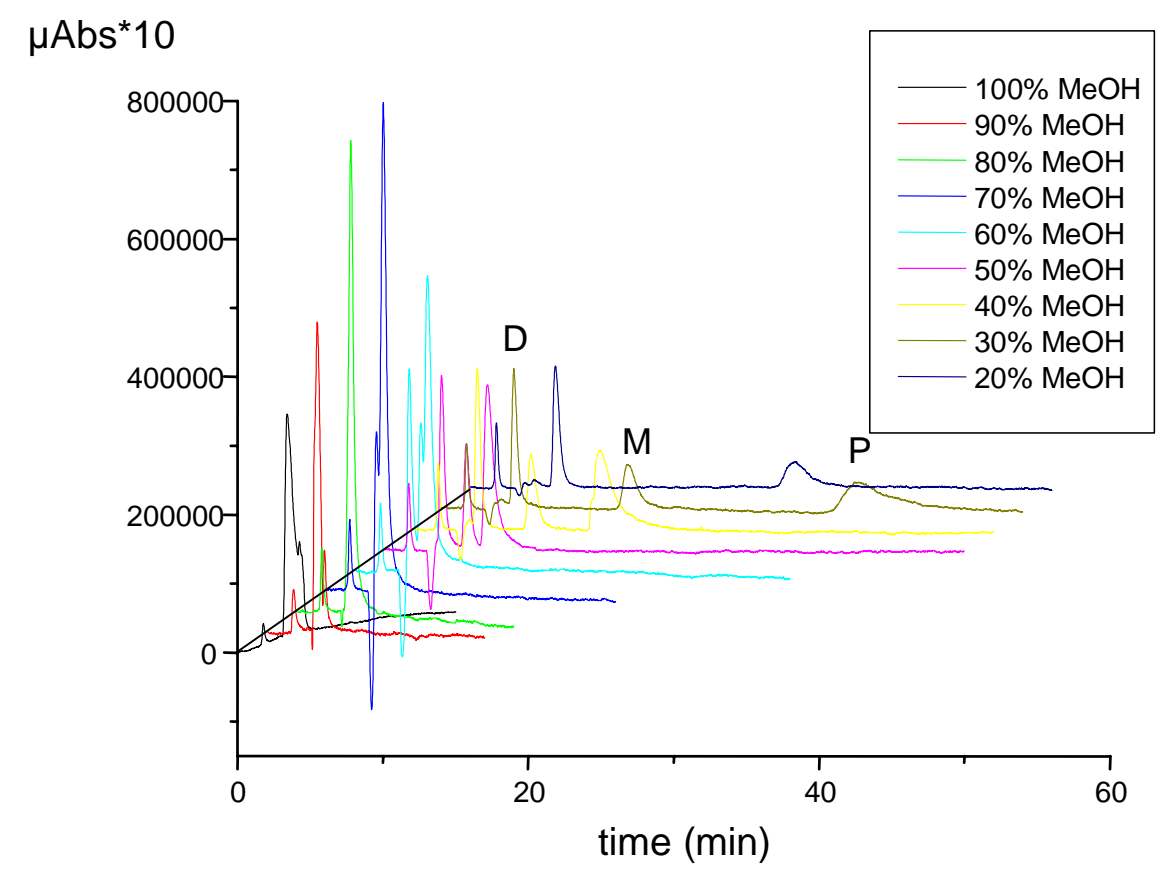

Figure 4 : Influence of $\mathrm{MeOH}$-content on the retention time of pesticides

Chromatographic conditions:

Stationary phase: Caltrex ${ }^{\circledR} \mathrm{BI}$

Mobile Phase: $\mathrm{MeOH} /$ water, flow 0,8 $\mathrm{ml} / \mathrm{min}$, injection volume $50 \mu \mathrm{l}$, concentration $0,01 \mu \mathrm{g} / \mu \mathrm{l}$

$\left(\mathrm{t}_{0}(\mathrm{MeOH})=1,80 \mathrm{~min}\right)$

D: dimethoate, $\mathrm{M}$ : methidathion, $\mathrm{P}$ : penconazole

\section{References}

1. Becker, G.and Schug, P.(1990). Miniaturized method for rapid determination of pesticide residues in foods of plant origin“, Dtsch. LebensmittelRundschau 86, 239 -242

2. Kalix, P. (1992). "Cathinone, a natural amphetamine”, Pharmacol. Toxicol. 70: 77- 86

3. Lee, S. M. ; Papathakis, M. L.; Hsiao-Ming C.Feng; Hunter, G. F. and Carr, J. E. (1991). "Multipesticide residue method for fruits and vegetables: Californic Department of Food and Agriculture”, Fresenius J. Anal. Chem. 339: 376- 383 
Afr. J. Trad. CAM (2006) 3 (1): 1 - 10

1. Luke, M. A.; Doose, G. M. (1983).” A modification of the Luke multiresidue procedure for low moisture, nonfatty products” Bull. Environ. Contam. Toxicol. 30: $110-116$

2. Szendrei, K. (1980). “The chemistry of Khat”, Bull. Narc. 32 (3): 5 - 36. 